\title{
HEALTH PROBLEMS OF FOREIGN WORKERS
}

Migration is a phenomenon largely associated with economic and human resource needs or, at the extreme, survival. Although considerably less substantial than in North America andWestern Europe at present, migrant labour is deemed to play an increasingly prominent role in the socio-economic development of the Asia Pacific region (I). In fact, 'importer' countries such as Malaysia and Singapore will depend on migrant workers to sustain its economic development while enabling 'exporter' countries, namely Indonesia, Philippines, Thailand, Bangladesh, Pakistan and Myanmar, to support its growing population and earn much needed income. The issues involved with immigrant workers include control over population movements, permanent residence, security risk, crime rates, exploitation and abuse, recruitment costs and impact on local populations. Examples are limits on work opportunities for local labour due to depressed wages, sharing of government subsidized schooling, low-cost housing and health care and other amenities with migrants and their children, and cost of arrest, detention and deportation of illegal immigrants.

Malaysia is both an importer as well as an exporter of human resources; requiring largely low-skilled labour from other countries and providing more skilled manpower to countries such as Singapore, Hong Kong and Japan where wages are considerably higher. In fact, migration has played a significant historical role over centuries (2). In the post-independence period, the use of migrant labour increased in the seventies. Foreign workers were brought in to work in the agricultural and plantation sectors vacated by local workers who moved to urban areas for employment and other opportunities following the implementation of the national New Economic Policy (3). In Sabah, the early seventies witnessed substantial migration from southern Philippines due to political disruptions (2). In-migration of labor increased further in the eighties when Malaysia placed a greater thrust on industrialisation and urban development. Then, migrant workers in the country were from Indonesia and Thailand, followed by Philippines, Myanmar and Bangladesh. A small minority came from elsewhere, including countries in Africa. Illegal migration continued to be a problem, because of Malaysia's proximity to source countries, multiple entry-points, bureaucratic hassles with the legalisation process, high recruitment costs and low wages (3).

Estimates place the number of immigrant workers in Peninsula Malaysia at around one million, of which nearly 600,000 are documented with legal status (3). However, the actual situation is unknown. Based on figures of illegal immigrants who underwent a nation-wide registration exercise between November 1991 and June
$1992,83.2 \%$ of the 372,268 were Indonesians. Based on employment, the majority of legal workers are engaged in the agricultural sector (primarily Indonesians and Thais) followed by domestic service (primarily Philippines), construction, manufacturing and service industry, including tourism and leisure (4). Most immigrant workers are residing in the more developed parts of the country. Majority of migrant workers mainly from Philippines and Indonesia, are found in substantial numbers. Certain urban areas such as Kudat Semporna, Sandakan and Tawau have substantial numbers of foreign workers, (5). Migrant workers were at first "invisible" to most Malaysians when they were isolated on rural plantations and land settlements. Over the years, they have become more conspicuous as they took up jobs in urban areas.

Concern over the influx of migrants stem from competition with local communities for jobs (both formal and informal sectors), for low-cost or squatter housing and other amenities, and improprieties in behaviour arising from cultural differences (3). Their willingness to accept low wages and poor living and working conditions was felt to favour migrant workers in job recruitment. The rising prejudice is exacerbated by media highlights of criminal activities among migrant workers, particularly with respect to violent crimes armed robberies and rapes. Although migrants commit a minority of all crimes in the country (3\% in 1991), there is widespread perception that most burglaries, for example, are perpetrated by this group, especially by Indonesians. With regards to type of crime, $48.2 \%$ of gang robberies and $18.2 \%$ of murders ( 1991 data), involved migrant workers. This trend has prevailed since 1985 (3).

In terms of health implications, migration is associated with changes in lifestyle, living conditions and socioeconomic status. Importer countries are concerned about diseases or carriers that migrants bring in whereas migrants are exposed to host-country diseases, acute or chronic (6), as well as problems accessing health and social services. A mild disease for the local community may manifest with increased severity in migrants who come from areas where the disease is not endemic and vice-versa. Furthermore, the stress of relocation and adaptation may influence susceptibility to illnesses (7).

Up to 1990 there has been only one study on the effectiveness of a screening program for intestinal parasites among refugee populations. This randomised controlled trial offered screening and treatment to one group and no screening to a control group. The study demonstrated a significant decrease in the prevalence 
of hookworm and Ascaris infections in the screened group after six months. However it was also found that the prevalence of Giardia and Strongyloides infections were not shown to be significantly different between the screened group and the controlled group after the six month study period.

Similarly in Malaysia, the presence of migrant workers raises questions on their health care needs, and the impact on local morbidity patterns. In Sabah, where the migrant population is sizeable, $35 \%$ of cases in major outbreaks of cholera and the majority of deaths due to this illness $(69 \%)$ have occurred among this group Outbreaks of measles in Sabah also occur in migrant settlements and among foreign workers, many of whom are migrants, living in poorly served "kongsi" shelters at construction sites (8). A study in urban areas of Sabah also revealed migrant respondents as having lower educational attainment, household income and provision of basic amenities, namely, treated water supply and sanitary toilets (9). Among ever -pregnant women, significantly more migrants than citizens had never practiced contraception (modern or traditional), never had antenatal care during any pregnancy, had deliveries by a traditional birth attendant, and suffered infant, particularly neonatal, deaths (9). It was reported that $64 \%$ of 56 cases of abandoned infants in Kuala Lumpur, Selangor and Johor in 1993 were associated with illegal immigrant women (3). This suggest a need for targeted contraceptive and health services and, clearly, implies a lack of social support. There is anecdotal evidence of migrants having limited access to preventive care and seeking treatment late, both of which have implications on health care cost. Since the exporter countries are at a lower stage of development, the entry of large numbers of migrants is thought to increase risks of certain communicable diseases, some of which have been controlled, among local communities, e.g., tuberculosis, whooping cough and hepatitis (3). The crowded and poor housing conditions facilitate, disease transmission is also facilitated among this group, most of whom in the low-income bracket.

In terms of health care, migrants have access to public hospitals and clinics at nominal fees, as do Malaysian citizens. However, there has been no documentation of the proportion of patients who are migrants and the health care utilization patterns among this group. Although health care services are available, there may be barriers to utilization due to ignorance, lack of confidence, and problems with health care providers. Thus, they may never seek treatment or treatment may be sought late when their health problems have become more severe.

Dato' Prof. Dr Anuar Zaini Mohd Zain

\section{Editor}

In summary, there has been no or little documentation of the health status, health care needs and utilization patterns of migrant workers, the implications for public health care services and costs, as well as impact on disease patterns in the country. There is also a need to assess the prevalence of parasitic infections in the immigrant population in this country.

\section{References}

I. Gooneratne W, Martin P, Sazanami H (1994). Labour migration within Asia: an introduction. In: Regional Development Impacts of Labour Migration in Asia. Wilbert Gooneratne. Philip L Martin, Hidehiko Sazanami (eds). UNCRD Research Report Series No. 2. United Nations Center for Regional Development, Nagoya, Japan, pI-24.

2 Doral RF (1989). Foreign workers in Malaysia: issues and implications of recent illegal economic migration from the Malay world. In:The Trade of Domestic Helpers.Asian Pacific Development Centre, Kuala Lumpur, p287-316.

3. Kassim A (1996). Cross-national labour migration in the Asia Pacific region: current issues in Malaysia. Paper presented at the First International Meeting of the Asia-Pacific Migration Research Network (APMRN), Asian Research Center for Migration, Chulalongkorn University, Bangkok, Thailand, II - 13 March 1996.

4. Kassim A. (1995). Recruitment and employment of foreign workers in Malaysia. In: Dimensions of Tradition and Development in Malaysia. RokiahTalib,Tan Chee Beng (eds). Pelanduk Publications, Kuala Lumpur, pl63-202.

5. Yusuf K (1992). Population and health in Sabah. In: Population and Health Issues in sabah. Mohd Yaakub $\mathrm{H}_{j}$ Johari. Mohd. Ayub Amirdad (eds). Institute for Development Studies Sabah and Konrad Adanauer Foundation, Kota Kinabalu, Sabah.

6. WHO (1986). UNICEF/WHO inter-regional consultation on primary health care in urban areas. World Health Organization, Geneva.

7. Schwarz K (1966). Public health aspects of migration. In: Migration, Medical and Social Aspects. EW Wolstenholm Gordon, M O'Connor (eds). CIBA Foundation Report. JA Churchill, London, p27 - 33.

8. Mahathevan R (1992). Health status and the people of Sabah - pattern of morbidity and mortality. In: Population and Health Issues in Sabah. Mohd Yaakub Hi Johari, Mohd Ayub Amirdad (eds). Institute for Development Studies Sabah and Konrad Adenauer Foundation, Kota Kinabalu, Sabah.

9. Zulkifli SN, Khin MU, Yusuf K, Wong YL (1994). Maternal and child health in urban Sabah, Malaysia: a comparison of citizens and migrants.Asia Pacific Journal of Public Health vol. 7 (3): $151-158$. 